\title{
HET VERBAND TUSSCHEN IN- EN UITVOER.
}

Ieder weet, waarom in onze hedendaagsche maatschappij de meesten niet voortbrengen hetgeen zij zelve, maar hetgeen anderen noodig hebben; waarom schier elkeen door ruil zich van het noodige voorziet, in plaats van zijne behoeften onmiddellijk te bevredigen. Wij zouden ons kunnen voorstellen, dat de maatschappij uit een groot aantal op zich zelf staande groepen - gezinnen of familiën met hunne dienst- en werkboden - bestond, die onderling geen of weinig commercieel verkeer hadden. Maar niemand twijfelt er aan, of de voortbrenging zou bij zulk een maatschappelijke inrichting belangrijk minder zijn dan thans. Dank zij het ruilstelsel is verdeeling van arbeid, is fabriekmatige nijverheid, dus voortbrenging in het groot mogelijk. Men heeft dit niet alzoo te verstaan, dat verdeeling van arbeid en voortbrenging in het groot zonder den ruil ondenkbaar zijn te achten; zij zijn niet alleen denkbaar, maar zouden misschien nog veel doeltreffender zijn toe te passen dan thans geschiedt in een maatschappij, die geheel op communistische grondslagen rustte. Werd van overheidswege de voortbrenging geregeld en bestuurd, dan zou - Thomas Morus heeft dit reeds voor meer dan drie eeuwen opgemerkt - zonder twijfel veel beter gewaakt kunnen worden tegen krachtsen tijdsverspilling, veel beter gezorgd kunnen worden voor een doelmatige groepeering van werkkrachten en hulpmiddelen dan nu gewoonlijk mogelijk is. Deze voordeelen zouden wel door zeer groote nadeelen worden opgewogen; 
maar toch de verkeerde gevolgen van het communisme eenigszins temperen. Als wij verdeeling van arbeid en voortbrenging in het groot van het ruilstelsel onafscheidelijk noemen, mogen wij nooit vergeten, dat zij slechts onafscheidelijk daarvan zijn, zoolang het individueel eigendomsrecht wordt gehandhaafd. Gegeven dit recht, aannemende dat men de productiemiddelen niet in het bezit der gemeenschap wil brengen, kunnen wij verklaren: zonder het ruilstelsel moet de voortbrenging gebrekkig blijven; bij dat stelsel alleen kan zij rijke vruchten geven.

Besparing van moeite is hier derhalve het doel. Wij hebben een bepaald artikel noodig. Vervaardigen wij het zelve, dan krijgen wij daarvan 100 stuks. Vervaardigen wij in denzelfden tijd en met dezelfde kosten een zekere hoeveelheid van een ander artikel, zoo verkrijgen wij daarvoor in ruil 150 stuks van het benoodigde goed. Daarom geven wij er de voorkeur aan, dit laatste te doen. Zoo redeneeren wij wel is waar gewoonlijk niet. Geboren en opgevoed in een maatschappij, waar ruil en verdeeling van arbeid op groote schaal sedert lang worden toegepast, denken wij er niet meer aan langs een anderen weg in onze behoeften te voorzien. De sociale toestanden zijn daarenboven naar het ruilstelsel zoodanig gevoegd en geplooid, dat een ander stelsel door de meesten nauwelijks meer aangewend zou kunnen worden. Maar werd ons de vraag gedaan, waarom diegenen, die daartoe in de gelegenheid zijn, toch niet direct, maar altijd, ten minste hootdzakelijk, indirect hunne behoeften bevredigen, dan zouden wij antwoorden: omdat dit laatste hun voordeeliger schijnt. De overtuiging, dat het ruilstelsel het goedkoope stelsel is, tegenover dezelfde offers van tijd en moeite de grootste en de beste uitkomsten levert, is algemeen. Wilde de regeering ons dwingen het te verlaten, welk een verzet zou dit uitlokken!

Men kan nog meer zeggen. Het zou reeds tegenstand verwekken, zoo de regeering ons in het ruilverkeer met 
onze medeburgers eenigermate wilde beperken; dit verkeer, zonder het te verbieden, wilde bemoeilijken. Binnenlandsche tolliniën worden nergens meer geduld. Sedert Duitschland zijn tolverbond heeft ingevoerd, is er binnen de grenzen van dat rijk volledige handelsvrijheid, en hoezeer de economische denkbeelden daar te lande in de laatste jaren veel zijn veranderd, bespeurt men niet, dat op het punt van het binnenlandsch verkeer door iemand de oude toestand wordt terug gewenscht. Evenmin bestaat er een partij in Frankrijk, die den ruil tusschen de verschillende departementen, in Groot-Brittannie, die den handel tusschen Engeland en Schotland wenscht te belemmeren. Noord-Amerika heet protectionnistisch gezind; maar tusschen al de Vereenigde Staten heerscht onbeperkte vrijheid van in- en uitvoer. Wel bestaan in sommige landen nog gemeentelijke accijnsen; doch zij bestaan er alleen voor fiscale oogmerken, en waar zij zijn afgeschaft verheugt zich ieder in de vrijheid van beweging, die den binnenlandschen handel daardoor ten deel viel. De voordeelen van het ruilstelsel binnen de eigen landpalen worden dus algemeen erkend. Men beseft, dat de welvaart veel verliezen, maar niets winnen zou, werd de bevoegheid der ingezetenen om dat stelsel onderling op de ruimste schaal toe te passen verkort.

Er bestaat echter, naar men weet, volstrekt geen eenstemmigheid omtrent de vraag, of ook aan de burgers van verschillende landen vrijheid van ruil moet worden verleend. Dat het ruilstelsel besparing van moeite, vermeerdering van de uitkomsten der voortbrenging tot gevolg heeft, wordt gaaf toegestemd voor het binnenlandsch, niet voor het internationaal verkeer. Naar het oordeel van velen kan de vrije ruil met het buitenland onder bepaalde omstandigheden schadelijk wezen; schadelijk, omdat de goederen, die het buitenland ons levert, aan den vreemdeling worden betaald en deze betaling den eigen arbeider geen brood geeft. Men gaat niet zoover, den invoer ge- 
heel te willen verbieden, maar het wordt raadzaam geacht den invoer van bepaalde goederen aan hooge rechten te onderwerpen. Dan inzonderheid, wanneer het buitenland zoo handelt ten aanzien van onze voortbrengselen. Talrijke voorstanders heeft de leer, volgens welke vrijheid van internationaal ruilverkeer zeer wel te verdedigen zou zijn, indien de vrijheid volkomen ware, door alle staten werd verleend. Maar nu dit niet zoo is, zou men zich te wachten hebben voor te groote mildheid in het toelaten van goederen, althans tegenover hen, die niet dezelfde mildheid jegens ons betrachten.

Het is mij altijd voorgekomen, dat het beste middel om de onjuistheid dezer beschouwingen aan het licht te brengen gelegen is in de aanwijzing van het verband tusschen uit- en invoer. Wanneer men bewijst, dat het onmogelijk is den invoer te verminderen, zonder tevens en met een gelijk bedrag den uitvoer te doen dalen, ondermijnt men bet geheele gebouw, waarop het beschermend stelsel, maar ook het stelsel van fair lrade, rust. Het blijkt dan niet waar te zijn, dat den arbeider het brood uit den mond wordt genomen door de vreemde producten toe te laten. De goederen, die het buitenland ons zendt, voor zoover zij geen remises zijn voor renten, vrachten en diergelijken, zullen met andere goederen worden betaald; de betaling doet vraag ontstaan naar eigen arbeid, eigen kapitaaldienst, en men wint er niets bij, zoo men die vreemde goederen weert: van zelf zal dan ook het buitenland minder voortbrengselen van ònzen bodem, van ònze nijverheid verlangen. In een land, dat slechts uitvoerde, tenzij de uitvoer alleen tot voldoening van renten en verteringen van ingezetenen in het buitenland geschiedde, zou men eerlang den algemeenen stand der prijzen een verhooging zien ondergaan, en die verhooging zou ten slotte zoo sterk worden, dat de uitvoer geheel ophield. Want uitvoer, waar geen invoer tegenover staat, maakt de betalingsbalins zeer 
gunstig, duet dus groote hoeveelheden geld in het land vloeien, en geld heeft met alle overige zaken dit gemeen, dat het in waarde daalt, zoodra het overvloedig wordt. Waardevermindering van het geld nu is prijsverhooging van alle goederen en diensten.

Het ware onnoodig deze redeneering, die dikwijls en met de vereischte uitvoerigheid is voorgedragen, in het breede te herhalen; wie haar nog niet kent, leze haar na in het een of ander leerboek. Mijn doel is ditmaal een ander. Ik wensch de bedenkingen die tegen haar zijn ingebracht, te wederleggen. De schranderste protectionnisten gaan eindelijk inzien, dat zij of hun stelsel moesten prijsgeven, òf het afdoende, ik mag wel zeggen het vernietigende argument, dat aan het verband tusschen in- en uitvoer wordt ontleend, beantwoorden. Is het werkelijk alzoo, kan men geen nationale nijverheid door hooge douanerechten scheppen, zonder juist evenveel nationale nijverheid in den grond te boren, dan blijft ten aanzien van bescherming slechts dit te zeggen over, dat zij de goederen duur maakt, dus louter kwaad sticht. Dan wordt het ook een weinig zonderling, tegelijk spoorwegen aan te leggen, subsidies te geven aan stoombootondernemingen, tunnels te graven, havens te verbeteren, en door hooge rechten den invoer te belemmeren; want belemmering van den invoer is dan belemmering van alles, wat men door die spoorwegen en tunnels, die stoombooten en havens dacht te bevorderen. Het in- en uitvoer-argument tast het protectionnisme in zijn hartader aan, en sommige verdedigers van dit stelsel beginnen dit te begrijpen. Het wordt hun duidelijk, dat dit argument te ontzenuwen een quaestie is van leven of dood voor de leer, die zij bepleiten.

Wie zou niet bereid zijn, als groote belangen op het spel staan, zijne denkbeelden steeds aan nader onderzoek te toetsen? Nederland staat thans met Engeland alleen in de zuivere toepassing der vrije-handels beginselen. 
Dwaalt het daarin of niet? Is men schier overal op het rechte spoor gekomen, of betrad men overal elders een verkeerden weg, terwijl Nederland in een goede richting bleef? Zulke vragen zijn gewichtig en eischen kalme overpeinzing. Hierbij komt, dat het probleem der internationale prijsverhoudingen tot de moeilijkste behoort op economisch gebied. Men kan er nooit genoeg toe terugkeeren. Laat ons dan nagaan, welke kracht er schuilt in de bedenkingen, waarvan ik sprak, opdat blijken moge, of zij ons dwingen het groote argument ten gunste van den vrijen handel los te laten.

I.

Zij zijn twee in getal. Het eerste komt hierop neder, dat in- en uitvoer volstrekt niet altijd met elkander in evenwicht zijn. Er bestaan landen, welker invoer hun uitvoer verre overtreft, en andere, waar de uitvoer den invoer te boven gaat; en dat niet bij uitzondering, het een of ander jaar, maar geregeld, ja soms in toenemende mate. Ziehier bijvoorbeeld een opgave van de jaarlijksche in- en uitvoeren van Groot-Brittannië en Ierland: 1)

\begin{tabular}{|c|c|c|c|c|c|c|}
\hline gemiddeld in $1854-59$ & Invoer. & nillioen & $\begin{array}{l}\text { Uitv } \\
£ 139\end{array}$ & r. & \multicolumn{2}{|c|}{$\begin{array}{l}\text { Meer in voer. } \\
£ 30 \text { millioen. }\end{array}$} \\
\hline $1860-64$ & » 235 & 》 & " 182 & $"$ & 1 52 & 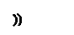 \\
\hline $1865-69$ & " 286 & » & ) 230 & ” & 》 56 & $"$ \\
\hline $1870-74$ & ) 346 & 》 & " 290 & $n$ & » 56 & ") \\
\hline $1875-80$ & 》) 375 & 》) & " 257 & 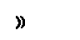 & ) 118 & $"$ \\
\hline $1881-84$ & 》 408 & $\eta$ & " 300 & $n$ & 》108 & $n$ \\
\hline
\end{tabular}

De invoeren, naar men ziet, overtreffen steeds de uitvoeren belangrijk. Van het omgekeerde geeft Britsch-Indië ons een voorbeeld:

Invoer. Uitvoer. Meer u itvoer. gemiddeld in $1873-78375$ milln ropijen 591 milln $^{\mathrm{n}}$ ropijen 216 mill $^{\mathrm{n}}$ ropijen 》 $1878-83466$ ” 》 736 » 270 ”

Hier zijn dus de uitvoeren sterk overwegend. Inderdaad is het niet te loochenen, dat tusschen uit- en invoeren

1) First Report of the Royal Commission appointed to inquire into the depression of trade and industry, bl. 127. 
soms ongelijkheid, ja groote ongelijkheid bestaat, en als de leer van den vrijen handel gegrond ware op deze stelling: in- en uitvoer zijn noodwendig en onder alle omstandigheden met elkander in evenwicht, zou zij niet zijn vol te houden. Wij zullen echter bespeuren, dat dit niet zoo is en dat er van onzen kant geen reden hoegenaamd bestaat om de ongelijkheid tusschen uit- en invoeren te verbloemen. Het beste middel om dit aan te toonen is hierin gelegen, dat wij de twee genoemde gevallen, dat van Groot-Brittannië en van Britsch-Indië, pogen te verklaren.

Beginnen wij met het geval van Groot-Brittannië. Oogenschijnlijk ligt de verklaring voor de hand. De reden, zoo pleegt men te zeggen, waarom de Britsche invoeren de uitvoeren te boven gaan, is, dat vele ondernemingen in allerlei streken met behulp van Engelsch kapitaal worden gedreven; dat Engeland en Schotland een uitgebreide scheepvaart hebben, dus in het buitenland veel vracht verdienen; dat zich in Groot-Brittannië veel buitenlandsche fondsen bevinden, waarvoor de rente geremitteerd moet worden. Winsten, vrachten, renten, ook bankiersprovisiën en diergelijken, al die posten - men heeft het wel eens nagecijferd, voor zoover dat ging maken te zamen een bedrag uit, dat vrij wel overeenkomt met het overschot der invoeren.

Is echter deze verklaring voldoende? $\mathrm{Zij}$ is het alleen voor hem, die volkomen is doordrongen van de leer, waarop het argument ten gunste van den vrijen handel is gebouwd. Zij is voldoende, wanneer men aanneemt, dat de hoeveelheid ruilmiddelen, die een volk noodig heeft, onder normale omstandigheden niet veel verandert, en dat, als eenmaal die behoefte is bevredigd, verdere toevoer waardevermindering van het geld, dus algemeene prijsverhooging zou teweegbrengen. Wie dit niet gelooft, wie het handelsverkeer in muntmetaal niet onderworpen acht aan dezelfde wetten, als waaraan het handelsverkeer in goederen gehoorzaamt, heeft aan het zoo even genoemdo niet genoeg. 
De gewone verklaring is voor hem in het geheel geen verklaring, maar slechts de uiteenzetting van iets, dat hem zeer raadselachtig moet voorkomen.

Hoe toch is de stand van zaken? Engelsche kapitalisten ontvangen bericht van zekere winsten, die ondernemingen, waarin een deel van hun vermogen is belegd, hebben opgeleverd; zij schrijven de beheerders dier ondernemingen aan hun die winsten te zenden. Engelsche reeders vernemen, dat hunne schepen in vreemde havens zijn binnengeloopen; bij voorbaat hadden zij reeds last gegeven hun de netto vracht te remitteeren. Engelsche fondsenhouders verkoopen hunne coupons aan bankiers; de bankiers zenden die coupons naar Amerika, naar Frankrijk, naar Rusland, en vragen het equivalent. Al deze personen, slechts diegenen uitgezonderd, die bij consignatie-contract toezending in goederen hebben bedongen, verlangen geld. En wat komt nu uit het buitenland en de koloniën? Suiker, tarwe, wol, vleesch, levend vee. De betalingsbalans scheen ongemeen gunstig; men zou denken: schatten gouds moeten in het land stroomen. Maar het gebeurt niet; met moeite houdt de Engelsche Bank haren goudvoorraad op het normale peil!

Nog eens, dit alles laat zich gemakkelijk ophelderen, zoodra men heeft leeren inzien, dat goud een gewoon handelsartikel is. Men redeneert dan aldus : in het buitenland is een levendige vraag naar wissels op Engeland: de beheerders van met Engelsch kapitaal gedreven ondernemingen, de correspondenten van Engelsche reeders, van Engelsche bankiers, zij allen moeten remitteeren, en slechts door uitvoer van het een of ander, dat in Engeland gewild is, kan het aanbod van wissels ontstaan, waaldoor die behoefte aan remise wordt bevredigd. Wat zal men nu uitvoeren? Men is misschien begonnen met geld te zenden; maar hierdoor werd het ruilmiddel schaarsch en daalden de prijzen, terwijl het ruilmiddel in Engeland door dezelfde oorzaak overvloedig 
werd en de prijzen daar stegen. Dientengevolge werd het voordeeliger goederen te zenden, en van daar, dat de getrokken wissels thans in goederen-, niet in gouduitvoer hun oorsprong vinden. Kortom, het edel metaal heeft zich zoodanig verspreid, dat prijsverhoudingen zijn ontstaan, die handel mogelijk maken. Door zoo te redeneeren neemt men echter aan, dat uit- en invoer van muntmetaal op de prijzen invloed hebben, en zoodra men dit aanneemt, kan men bezwaarlijk loochenen, wat door de voorstanders van den vrijen handel steeds wordt beweerd, dat uit- en invoer van goederen met elkander samenhangen. Want dit verband rust op de werking vall vermeerdering of vermindering der geldvoorraden op de prijzen. Bestaat die werking, of bestaat zij niet? Bestaat zij, dan is het duidelijk, dat een land, welks geldvoorraad voldoende is, geen uitwoerhandel kan drijven, tenzij invoerhandel daarmede gepaard gaat; anders toch zal er goud komen en dat goud zal de prijzen doen stijgen, hetgeen den uitvoer van zelf doet eindigen. Bestaat zij niet, dan vervalt natuurlijk deze bewijsvoering, maar dan is het evenmin verklaard, waarom een land als Engeland, dat jaarlijks voor 100 millioen pond sterling aan vrachten, renten, winsten en provisiën van het buitenland te vorderen heeft, dat bedrag juist in goederen ontvangt.

De geheele toestand, dien men ons schetst en dien men als een bezwaar tegen het vrije-handelsargument wil doen gelden, is derhalve slechts te verklaren, wanneer men toegeeft, dat dit argument op een gezonden grondslag rust. Of wil men het anders zien uitgedrukt? De omstandigheid, dat Engeland zijn 100 millioen niet in geld, maar in goederen ontvangt, bewijst, dat gestadige geldtoevoer naar een land, welks voorraad ruilmiddelen voldoende is, zich zelf verbiedt, immers prijsverhoudingen zou scheppen, waardoor goederenzendingen voor geldzendingen in de plaats zouden treden. 
De protectionnisten hebben dus geen gelukkigen greep gedaan door op die omstandigheid de aandacht te vestigen; zoodoende maakten zij ons indachtig aan een ervaring, die allen twijfel omtrent den invloed van de metaalbewegingen op de prijzen wegneemt. Zij drongen ons, naar de verklaring van de overmaat der invoeren, die zich in sommige landen laat waarnemen, te zoeken, en het blijkt nu, dat die verklaring slechts te vinden is bij een theorie, die aan het argument, waartegen men zich kant, tot uitgangspunt dient.

Maar ik wil hierop niet verder aandringen en liever de vraag stellen, wat uit die ongelijkheid der uit- en invoeren, waarop men wijst, ten bate van het protectionnisme kan worden afgeleid? Onze bewering luidt aldus : gij kunt de invoeren niet kunstmatig verminderen, of gij vermindert de uitvoeren tevens. Dit houdt toch niet op waar te zijn, zoo de invoeren de uitvoeren te boven gaan! Of zou men aldus willen spreken: Engeland voert in voor 400, voert uit voor 300 millioen pond sterling. Dalen nu door hooge rechten de invoeren tot 300 millioen, zoo behoeven de uitvoeren niet af te nemen; zij komen door die verandering dan juist met de invoeren in evenwicht? Deze redeneering zou hoogst gebrekkig zijn, daar zij de remises voor vrachten, renten en diergelijken geheel zou verwaarloozen. In welken vorm zouden die remises dan voortaan komen? In den vorm van geld? Engelands geldvoorraad wordt op 120 à 150 millioen pond sterling geschat; acht men het mogelijk, dat hieraan jaarlijks voor 100 millioen wordt toegevoegd? Komen zij echter, als voorheen, in den vorm van goederen, dan moet het oude verschil tusschen in- en uitvoer bewaard blijven, dus de overmaat der invoeren stand houden. Dit kan echter bij daling der invoeren van 400 op 300 millioen slechts geschieden, wanneer dèvoeren van 300 op 200 verminderen. Hetgeen te bewijzen viel.

Maar neen, ik vergis mij. Het zou toch mogelijk zijn 
dat de protectionnisten gelijk hadden. De hooge rechten zouden zoo nadeelig kunnen werken op den scheepsbouw, dat de Britsche vloot belangrijk kleiner werd; dientengevolge zou dan voor vracht veel minder dan thans te vorderen zijn. Zij zouden daarenboven door hunne werking op de prijzen zulk een verarming kunnen teweegbrengen, dat Engeland vele zijner buitenlandsche fondsen moest verkoopen en daardoor de jaarlijks voor rente te ontvangen som aanmerkelijk afnam. Door dit een en ander zou het hierboven bedoelde bedrag van 100 millioen pond sterling een zekere daling ondergaan. Stel, het daalde tot 50 millioen. Dan zouden de invoeren met 100 millioen kunnen afnemen, terwijl de uitvoeren slechts afnamen met de helft minder. De rekening werd dan aldus:

$$
\begin{array}{r}
\text { Invoer (eerst 400, nu) } \mathbf{3 0 0} \text { millioen } \\
\text { Uitvoer (eerst } 300, \mathrm{nu}) \\
250 \text { millioen } \\
\text { Te vorderen voor vrachteu, enz. } \\
\text { (eerst } 100, \mathrm{nu}) \quad 50 \quad \text { } \\
\frac{\mathbf{3 0 0} \text { millioen }}{}
\end{array}
$$

Tk erken, dat de gewone leer, volgens welke de invoeren niet kunstmatig kunnen verminderen, of de uitvoeren verminderen met een gelijk bedrag, deze verbetering noodig heeft. Zij houdt geen rekening met den schadelijken invloed der beschermende rechten op de voortbrenging, op de algemeene welvaart. $\mathrm{Zij}$ neemt niet in aanmerking, dat er een jaarlijks voor vrachten en renten te vorderen som kan zijn, die onder de werking dezer rechten geringer wordt. Ik verklaar mij bereid, deze wijziging in de leer aangaande het verband tusschen uiten invoer voor te staan. Maar wat de protectionnisten daarbij kunnen winnen, is mij niet duidelijk.

Het geval van Britsch-Indië behoeft ons niet lang bezig te houden. Een groot deel der Britsch-Indische publieke uitgaven wordt in Engeland betaald; Indië is uit dien hoofde aan Engeland jaarlijks een som schuldig, die in 
de jaren $1873-83$ dooreen $160,000,000$ ropijen heeft bedragen. De reden, dat Britsch-Indië voor dat bedrag geen geld, maar goederen zendt, is zeer eenvoudig. Indië kan geen ruilmiddelen missen, het voerde zelfs jaarlijks van 1873-83 voor 79 millioen ropijen aan goud en zilver in 1). Zond het telken jare voor $160,000,000$ ropijen aan muntmetaal naar Europa, dan zuuden de Indische prijzen en loonen door gebrek aan ruilmiddelen belangrijk dalen, hetgeen den uitvoer van goederen dermate prikkelen, den invoer dermate temperen zou, dat aan die geldverzendingen spoedig een eind zou komen. Maar dit alles sluit weder geheel met de theorie omtrent de werking van den voorraad ruilmiddelen op de prijzen, die, gelijk is opgemerkt, aan het vrije-handelsargument ten grondslag ligt. Het geval van Britsch-Indië bevestigt die theorie niet minder dan het geval van Groot-Brittannië. Hier, in Groot-Brittannië, is jaarlijks een groot saldo te vorderen: het $\mathrm{k}$ o $\mathrm{m} \mathrm{t}$ in goederen. Ginds, in Indië, is jaarlijks een groot saldo te betalen: het gaat in goederen. Maar welk voordeel de protectionnisten kunnen putten uit de vermelding dezer feiten, wil mij niet helder worden. Stel, door hooge rechten wist men in Britsch-Indië de invoeren, die in 1873-83 jaarlijks 421 millioen ropijen hebben bedragen, tot 300 millioen terug te brengen; hoe zou de rekening dan sluiten, tenzij ook de uitvoeren in gelijke mate verminderden? Geeft men ten antwoord, dat in zoodanig geval de 79 millioen, die Britsch-Indië jaarlijks aan goud en zilver trekt, tot 200 millioen zullen aanzwellen, zoo zal toch wel ieder toestemmen, dat die voorstelling elken redelijken grondslag mist en dus volmaakt willekeurig is.

De eerste bedenking schijnt mij hiermede opgelost. De

1) In 1873-83 was de rekening (gemiddeld per jaar') als volgt:

Vitvoer van goederen 663 millioen rop. Invoer vau goederen 421 mill. rop.

" "goud en zilver 79 "

Traites der Britsche regeering 160 "

$6 \overline{60}$ mill. rop. 
stelling, waartegen zij gekant is, luidt aldus: de invoer kan niet verminderen, of de uitvoer vermindert in dezelfde mate. Dit beteekent niet, dat in- en uitvoer noodwendig met elkander in evenwicht zijn, maar dat, voor zoover zij van elkander verschillen, het verschil bij kunstmatige vermindering der invoeren bewaard zal blijven. Is de invoer $x$, de uitvoer $y$, dan zal, zoo de invoer daalt tot $x-z$, de uitvoer dalen tot $y-z$. Wel is het nu gebleken, dat deze stelling te ver gaat; dat hooge rechten in een land, waar de invoeren overwegend zijn, dat overwicht geringer kunnen maken. Maar wij zagen tevens, dat deze verbetering van de bestaande theorie aan het protectionnisme niet ten goede komt, daar zij slechts aannemelijk is voor hem, die aan hooge invoerrechten een nadeelige werking op de algemeene welvaart toeschrijft.

\section{II.}

De tweede bedenking heeft dezen inhoud. Het is waar, dat in- en uitvoeren met elkander samenhangen; doch wanneer men die woorden: in- en uitvoer bezigt, mag men niet alleen aan goederen denken, want ook effecten spelen in het handelsverkeer een belangrijke rol. Gesteld nu, een land verhoogt zijne invoerrechten, zoodat het bedray zijner goedereninvoeren belangrijk vermindert. Daarom behoeven zijne uitvoeren van goederen niet te verminderen, want het is zeer wel mogelijk, dat voor goedereninvoer effecteninvoer in de plaats komt. De betalingsbalans blijft dan ongewijzigd.

Bijvoorbeeld: de invoer is jaarlijks / 300 millioen, de uitvoer even groot, en beide bestaan alleen uit goederen. Daalt $\mathrm{nu}$ door hooge rechten de goedereninvoer tot f 200 millioen, maar ontstaat tegelijk een effecteninvoer van $f 100$ millioen in het jaar, zoo kan de uitvoer stand houden op het oude cijfer. En het is waarschijnlijk, dat de loop van zaken aldus zal zijn, want de bescher- 
mende rechten zullen veel rijkdom in het land brengen, dus velen tot aankoop van effecten in staat stellen.

Laat ons deze redeneering van naderbij bezien en daarbij vooral niet vergeten, dat aan ieder effect een couponblad is bevestigd.

Eenvoudigheidshalve stellen wij, dat de ingevoerde fondsen alle 5 percent rente geven. Deze rente is nu door het buitenland verschuldigd en bedraagt bij een jaarlijkschen toevoer van $f 100$ millioen in het eerste jaar 5 , in het twee 10 , in het twintigste $\mathbf{1 0 0}$ millioen. Met andere woorden: een land, dat steeds effecten invoert, komt meer en meer in den toestand van een groot saldo te moeten vorderen van het buitenland, en men heeft ons in te lichten omtrent de vraag, hoe dat saldo zal worden verrekend? In het twintigste jaar, gesteld, dat de goederen-uitvoer niet gestegen is, zal het totaal der invoeren van goederen en effecten te zamen tot / 400 millioen moeten geklommen zijn, want voor / 300 millioen zal er te vorderen zijn wegens de uitvoeren, voor / 100 millioen wegens de renten. Wij hebben noodig te weten, hoe die $/ 400$ millioen zullen zijn verdeeld.

Zullen zij nog altijd voor slechts $f 100$ millioen bestaan uit effecten? Helaas, dan hebben de invoerrechten niet veel uitgericht, want dan zijn de invoeren van goederen in weerwil van de rechten, tot / 300 millioen geklommen. De gestadige vermeerdering van het rentebedrag heeft dan de werking der hooge rechten te niet gedaan, immers de goedereninvoeren teruggebracht tot het oude cijfer. Van lieverlede is dat geschied; hoe meer effecten er kwamen, des te meer namen de invoeren van goederen toe, verdween dus het aanvankelijk verkregen (voordeel» hunner vermindering. Als men twintig jaar verder is, zal de toestand, uit een protectionnistisch oogpunt bezien, op nieuw ongunstiger zijn geworden. De jaarlijks voor rente te vorderen som is dan verdubbeld, en komt die som in goederen, zoo zal de goedereninvoer $f 400$ millioen bedragen. Wij 
onderstellen, gelijk men weet dat de uitvoeren onveranderd zijn gebleven; zijn zij vermeerderd, zoo moet de invoer nòg hooger zijn.

Het is mij niet gebleken, of de protectionnisten zich bet beloop inderdaad zoo voorstellen. Mij dunkt echter, dit kan niet zoo zijn; het zou hun stelsel onder een te wonderlijk licht brengen. Het doel van hooge rechten is den invoer van goederen te temperen; maar gestadige effecten-toevoer tot een gelijk, nonit klimmend bedrag, brengt een jaarlijks ver me er d er en d en invoer van goederen teweeg. Als hooge rechten een oorzaak scheppen, die dit gevolg heeft, beantwoorden zij waarlijk niet aan de verwachting, die men er van koestert en doet men beter ze niet te heffen. Een protectionnist moet het gelukkiger achten, dat de invoeren onveranderd op / 300 millioen blijven, dan dat zij aanvankelijk dalen tot $f 200$ millioen, maar daarna elke twintig jaren $\int 100$ millioen stijgen. Ik vermoed dus, dat men zich den loop van zaken anders denkt. Zonder twijfel neemt men aan, dat met het klimmend rentebedrag een klimmende invoer niet van goederen, maar van effecten zal gepaard gaan. De $f 100$ millioen aan effecten, die het eerste jaar worden ingevoerd, worden dan $/ 105$ millioen in het tweede, $f 110,250,000$ in het derde, $f 115,512,250$ in het vierde. Het rentebedrag groeit naar deze onderstelling veel spoediger aan; niet na 20, maar reeds na 15 jaren ongeveer bedraagt het $f 100,000,000$, en elke volgende 15 jaren wordt het verdubbeld. $\mathrm{Na} 45$ jaren zal het gestegen zijn tot $f 400$ millioen, welke som, gevoegd bij het verschil tusschen de uit- en invoeren, tot $/ 500$ millioen klimt. $\mathrm{Na} 60$ jaren zal het jaarlijks te verevenen saldo $f 900$ millioen bedragen.

Immers; wegens de uitvoeren zal te vorderen zijn. . . f 300 millioen wegens renten . . . .

Hiervan gaat af wegens den invoer van goederen.$\cdot \frac{200}{\text { Blijft }} \cdot \frac{.}{f} 900$ millioen 
Maar bedrieg ik mij niet, zoo brengt deze uiteenzetting de tegenpartij in een moeilijk dilemma. Een van beiden: of zij moet beweren, dat de toevoer van effecten niet zal vermeerderen, maar dan is het duidelijk, dat de hooge rechten, van haar standpunt bezien, meer kwaad dan goed stichten; òf zij moet aantoonen, dat die toevoer wel zal vermeerderen, maar dan is zij gedwongen een stelling te verdedigen, waarvoor geen redelijk argument is bij te brengen. Die stelling toch komt hierop neder, dat àl de rente, die van de aangevoerde effecten wordt genoten, zal worden opgelegd en tot aankoop van nieuwe buitenlandsche effecten besteed. Natuurlijk is er niemand, die dit waarschijnlijk acht, niemand zeker, die het op gezag der protectionnisten of van wie ook zal gelooven.

En vraagt men eenmaal naar bewijsgronden, dan zal men meer vragen. Men zal willen weten, of zich inderdaad laat verwachten, dat, wanneer hooge rechten den invoer van goederen verminderen, invoer van effecten tot het volle bedrag van die vermindering zal ontstaan. De protectionnisten zeggen misschien: er zal binnenslands meer worden verdiend. Toegegeven voor een oogenblik, doch er moet nog iets anders worden bewezen. Te bewijzen valt $1^{0}$, dat er juist zóóveel meer verdiend zal worden, als mindel wordt ingevoerd. Voor / 100 millioen aan buitenlandsche goederen komen / 100 millioen aan binnenlandsche voortbrengselen in de plaats; men moet nu aantoonen, dat de daardoor verkregen vermeerdering van nationaal inkomen honderd percent van de waarde dezer voortbrengselen zal bedragen. Te bewijzen valt $2^{0}$, dat die winst geheel zal worden opgelegd. Geeft zij aanleiding tot grooter vertering, zoo is de rekening in de war. Te bewijzen valt $3^{*}$, dat de opleg uitsluitend zal geschieden door aankoop van buitenlandsche fondsen. Gaat men land verbeteren, fabrieken bouwen, zoo heeft die aankoop geen plaats. Waar is deze drievoudige bewijsvoering te vinden? Ik heb zelfs nooit een 
antwoord gevonden op de zoo even gestelde vraag: hoe men zich voorstelt, dat het steeds klimmend rentesaldo door het buitenland zal worden aangezuiverd?

Inderdaad is het dringend noodig, dat men zich nader verklaart. Het effecten-argument maakt thans den indruk van een noodschot te zijn, een uitvlucht, een wanhopige poging om zich te onttrekken aan het antwoord op de vraag: als de invoer kunstmatig wordt verminderd, wat zal dan met den uitvoer geschieden? Men kàn niet zeggen: dan zal de uitvoer dalen met een gelijk bedrag, want dan zou men toegeven, dat hooge recliten evenveel nationale nijverheid vernietigen als te voorschijn brengen. Men wil niet zeggen: dan zal de uitvoer voor een deel met geld worden betaald, want men begrijpt, dat gestadige vermeerdering van den geldvoorraad zich zelf verbiedt. Nu zegt men: de ledige plaats bij den invoer zal door effecten worden aangevuld. Men bewijst dit niet, men geeft zich geen rekenschap van hetgeen die bewering insluit, men verzekert het eenvoudig, en lost de problemen niet op, die deze verzekering doet ontstaan.

De protectionnisten moeten nu aantoonen, dat onze indruk verkeerd is. Stellen zij prijs op eene wetenschappelijke wederlegging hunner denkbeelden, zoo moeten zij beginnen met een wetenschappelijke uiteenzeting te geven van die denkbeelden, en wetenschappelijk is in de eerste plaats volledig, duidelijk. Onze voorstelling van het verband tuschen in- en uitvoer, beweren zij, is onjuist; welnu, dat zij ons zeggen, welke voorstelling haar vervangen moet. Het zou niet waar zijn, dat internationaal, even goed als elk ander ruilverkeer besparing van moeite, vermeerdering van de uitkomsten der voortbrenging tot gevolg heeft; welnu, laat ons hooren, waarom niet; waarom het nuttıg zou zijn een Groninger vrij te laten ruilen met een Fries, maar schadelijk tot op zekere hoogte een Nederlander te laten ruilen met een Belg. Niemand beweert, dat een boer verarmt, wanneer hij slechts boter 
en kaas maakt en zijne kleederen door anderen laat maken; waarom verarmt een geheel volk dan wel, wanneer het zich sommige goederen in het buitenland aanschaft? Is het een niet hetzelfde als het ander, men bewijze het ons. Wij zijn bereid kalm te luisteren naar hetgeen men ons te zeggen heeft. Alleenlijk, men late ons niet rondtasten in bet donker, wanneer wij trachten na te gaan, welke begrippen men tegenover de onze stelt.

En ook dit is te eischen, dat men het argument, aan het verband tusschen in- en uitvoer ontleend, niet stilzwijgend voorbij ga. Dat geschiedt veelvuldig; nog onlangs is het gebeurd in de proclamatie aan de kiezers, die de Tweede Algemeene bijeenkomst van Nederlandsche Industrieëlen heeft vastgesteld. "Het werk, dat in Nederland kan gedaan, het brood dat in Nederland verdiend kan worden, ". zoo leest men in dat stuk, «komt allereerst en allermeest Nederlanders toe.... Leve de nationale arbeid! Hij is de beste, de meest natuurlijke waarborg voor algemeene welvaart, tevredenheid en orde.) Dit is zeer welsprekend, maar heeft slechts zin, wanneer het toelaten van vreemde producten den nationalen arbeid in gevaar brengt, den werkman zijn brood ontneemit. Ik zoek in het geheele verslag der zitting te vergeets naar een enkel woord, waar de juistheid dezer voorstelling tegenover het bovengenoemde argument wordt bepleit. Heeft men dit volkomen overbodig geacht? Mij komt het voor, dat men juist daaraan den meesten tijd had moeten geven.

N. G. Pierson. 